\title{
越流型水制周辺の三次元乱流構造に及ぼす 水理パラメータの効果 \\ EFFECTS OF HYDRAULIC PARAMETERS ON 3D TURBULENT FLOW STRUCTURES AROUND SUBMERGED SPUR-DIKES
}

\author{
木村 一郎 1 ・細田 尚 2 ・音田 慎一郎 3 ・冨永 晃宏 4 \\ Ichiro KIMURA, Takashi HOSODA, Sinichiro ONDA and Akihiro TOMINAGA

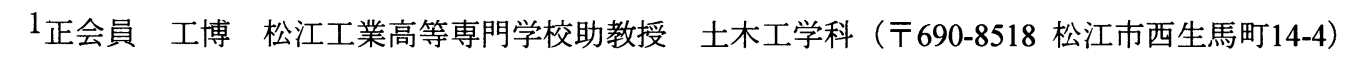 \\ 2 正会員 工博 京都大学大学院教授 工学研究科都市社会工学専攻（广606-8501 京都市左京区吉田本町） \\ 3学生員 工修 京都大学大学院工学研究科博士課程学生（广T606-8501 京都市左京区吉田本町） \\ 4正会員 工博 名古屋工業大学大学院教授 工学研究科社会開発工学専攻（广466-8555 名古屋市昭和区御器所町）
}

\begin{abstract}
This paper describes the numerical study on 3D turbulent flow structures around submerged spur-dikes. Effects of three hydraulic parameters, S/L (S: interval of two spur dikes, L: length of spur dikes), T/h (T: height of spur dikes, h: depth), $\theta$ (=inclination angle), are examined through the comparison of numerical results and previous experimental results focusing on both time-mean and time-dependent aspects. A non-liner k- $\varepsilon$ model is adopted as a turbulence model to reproduce the vortex shedding from a tip of a spur-dike and secondary currents. The numerical results show that, the flow near the bed, which is particularly important for sediment transport, is affected by both inclination angle and the ratio $\mathrm{T} / \mathrm{H}$. In the downstream inclined spur dikes, the unsteady vortex shedding is generated and the period is determined by the feedback effect of impinging shear layer. The frequency jump of the vortex shedding can be seen between $\mathrm{S} / \mathrm{L}=2$ and $\mathrm{S} / \mathrm{L}=4$ in the numerical results.
\end{abstract}

Key Words : submerged spur-dike, non-linear $k$ - $\varepsilon$ model,3D numerical simulation, $R A N S$, turbulent open channel flow, impinging shear layer, feedback effect

\section{1.はじめに}

伝統的河川工法の一つである水制は, 元来, 治水, あ るいは水運のための構造物であったが，近年は河川環境 向上のための構造物という意味合いが強まってきている. 例えば，木兽川等では約100年前に設置された水制周辺 にワンド群が形成され，良好な河川環境が創出されてい $る^{1)}$ ことなとから，人工ワンドの形成を主目的とした環 境指向型の水制設置の試みも行われ始めた. 水制等の構 造物を河道中に設置するにあたっては，治水と環境の両 面から周辺の局所洗掘や土砂堆積に対して十分な検討が 必要であることはいうまでもなく，このためには構造物 周辺の流れ構造を詳細に検討する必要がある.

このような背景をうけて, 水制周辺の流れに関する研 究は, 実験的あるいは数值解析的手法を駆使して盛んに 行われるようになってきた. 水制周辺の流れ場の特徵は, 水制間の循環流形成，水制根元付近の渦形成といった三 次元性と，水制先端からの渦の発振に伴う非定常性に特 徴付けられる.このような流れ構造を詳細に把握するた
めには，流れ場の広い範囲の情報を時間的に連続に取得 する必要があるため, 実験的手法としてはPIVなどの画 像解析法が有効であり, 数值解析では非定常三次元解析

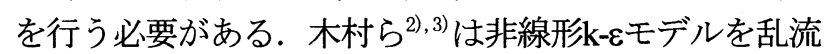
モデルとして用いた数值解析手法により冨永ら出の行っ た実験(PIV)の再現計算を行い，数值解析法の有効性を 確認するとともに，水制間の時間平均流，非定常特性の 双方が水制設置角度に大きく影響されることを確認した. また，水制周辺の渦形成過程は流体力学の古典的テーマ の一つであるimpinging shear layerのそれと同類であるこ と，また，水制群においては第一水制の水刎ね効果が渦 発振に最も寄与することなどが示された. 冨永ら ${ }^{5)}$ は水 制間隔を 3 通りに変化させた条件でPIV計測を行い，時 間平均流れ場の変化を検討した. これらの結果はそれぞ れ有益な示唆を与えるものであるが，実際的な水制設置 に役立つ資料とするためには，より多くのパラメータに ついて系統的な検討を進めていく必要がある.

本研究では, 水制周辺の流れ構造と水理パラメータの 関係について，主に数值解析により検討を行ったもので 
ある，検討パラメータは，水制設置角度，水制間隔/水 制長, 水制高 / 水深の 3 つする. 数值解析モデルとし ては，計算機負荷と精度とのバランスを考慮し，かつ水 制域への適用性が検証されている移動一般曲線座標系に おける非線形k-とモデルを基礎とするモデルを採用する。 計算条件の一部は冨永らの実験5) と同条件に設定し，実 験結果と計算結果の比較を通じて現象解明を試みる.

\section{2. 数值解析法}

\section{（1）基礎式}

本研究で用いる移動一般曲線座標系における反変成分 表示の基礎式(6),7),8) を次に示す.

[連続式 $]$

$$
\frac{1}{\sqrt{g}} \frac{\partial V^{\alpha} \sqrt{g}}{\partial \xi^{\alpha}}=0
$$

[運動方程式]

$$
\begin{aligned}
\frac{\partial V^{i}}{\partial t} & +\nabla_{j}\left[V^{i}\left(V^{j}-W^{j}\right)\right]+V^{i} \nabla_{j} W^{j}+V^{j} \nabla_{j} W^{i} \\
& =F^{i}-\frac{1}{\rho} g^{i j} \nabla_{j} p+\nabla_{j}\left[-\overline{v^{i} v^{j}}\right]+2 V \nabla_{j} S^{i j}
\end{aligned}
$$

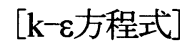

$$
\begin{aligned}
\frac{\partial k}{\partial t} & +\nabla_{j}\left[k\left(V^{j}-W^{j}\right)\right]+k \nabla_{j} W^{j} \\
& =-g_{i l} \overline{\nu^{l} v^{j}} \nabla_{j} V^{i}-\varepsilon+\nabla_{j}\left\{\left(\frac{D_{t}}{\sigma_{k}}+v\right) g^{i j} \nabla_{i} k\right\}
\end{aligned}
$$

$\frac{\partial \varepsilon}{\partial t}+\nabla_{j}\left[\varepsilon\left(V^{j}-W^{j}\right)\right]+\varepsilon \nabla_{j} W^{j}=-C_{\varepsilon 1} \frac{\varepsilon}{k} g_{i l} \overline{v^{l} v^{j}} \nabla_{j} V^{i}$

$-C_{\varepsilon 2} \frac{\varepsilon^{2}}{k}+\nabla_{j}\left\{\left(\frac{D_{t}}{\sigma_{k}}+v\right) g^{i j} \nabla_{i} \varepsilon\right\}$

ここに, $\xi^{j}$ : 計算空間の空間座標, $t$ : 時間, $V^{j}$ : 流速べ クトルの反変成分, $\mathrm{W}^{j}$ : 格子移動速度ベクトルの反変成 分, $v^{j}$ : 乱れ速度ベクトルの反変成分, $p$ : 圧力, $v$ : 動 粘性係数, $\rho$ : 流体の密度, $k$ : 乱れエネルギー, $\varepsilon$ : 乱 れエネルギー散逸率, $F^{j}$ : 重力ベクトルの反変成分をそ れぞれ表わす． $g_{\mathrm{ij}}, g^{\mathrm{j}}$ は計量テンソルの共変成分及び反変 成分であり, 次のような関係がある.

$$
g_{i j}=\frac{\partial x^{k}}{\partial \xi^{i}} \frac{\partial x^{l}}{\partial \xi^{j}} \delta_{k l}, g^{i j}=\frac{\partial \xi^{k}}{\partial x^{i}} \frac{\partial \xi^{l}}{\partial x^{j}} \delta_{k l}, g_{i j} g^{j k}=\delta_{i}^{k}
$$

ここに， $x^{j}$ はデカルト座標系を表す．また，

$$
g=\operatorname{det}\left[g_{i j}\right]
$$

である，さらに， $\nabla_{\mathrm{j}}$ は共変微分を表し，例えば，あるべ クトルの反変成分 $A^{\mathrm{k}}$ に関しては, 次のようになる.

$$
\nabla_{i} A^{k}=\partial A^{k} / \partial \xi^{i}+A^{j} \Gamma_{i j}{ }^{k}
$$

ここに, $\Gamma_{\mathrm{i} j}{ }_{\mathrm{j}}^{\mathrm{k}}$ はクリストッフェルの記号（接続の係数） であり, 次式で計算される.

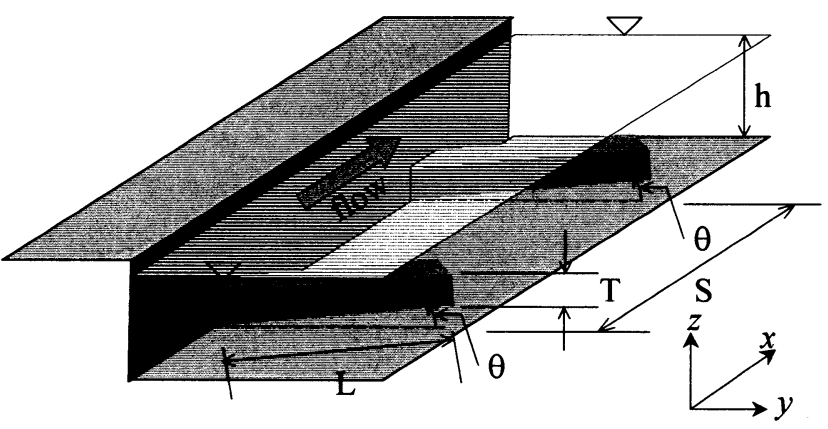

図-1 流れ場の模式図と記号の説明

$$
\Gamma_{i j}{ }^{k}=\left\{\begin{array}{c}
k \\
i j
\end{array}\right\}=\frac{1}{2} g^{k m}\left(\frac{\partial g_{j m}}{\partial \xi^{i}}+\frac{\partial g_{i m}}{\partial \xi^{j}}-\frac{\partial g_{i j}}{\partial \xi^{m}}\right)=\frac{\partial \xi^{k}}{\partial x^{p}} \frac{\partial^{2} x^{p}}{\partial \xi^{i} \partial \xi^{j}}
$$

なお，流速べクトルの反変成分 $\left(V^{k}\right)$ と直交成分 $\left(U^{k}\right)$ は次 の関係 (chain rule) により変換される.

$$
V^{i}=\left(\partial \xi^{i} / \partial x^{j}\right) \cdot U^{j}, \quad U^{i}=\left(\partial x^{i} / \partial \xi^{j}\right) \cdot V^{j}
$$

\section{（2）乱流モデル}

乱流モデルには，二次流や剥離渦の再現性，壁面が粗 面である点を考慮して，著者らが開発を行ってきた高レ イノルズ数型二次非線形 $k$ モモデルを用いる. 本モデル は角柱 ${ }^{9)}$ や立方体周辺の流れ ${ }^{10)}$ ，複断面開水路流れ ${ }^{11)}$ な どへの適用性が検証されている. 非線形 $\mathrm{k}$ モモデルの一 般曲線座標系における構成則を次に示す ${ }^{12)}$.

$$
\begin{gathered}
-\overline{v^{i} v^{j}}=D_{t} S^{i j}-\frac{2}{3} k g^{i j}-\frac{k}{\varepsilon} D_{t}\left[\alpha_{1} Q_{1}+\alpha_{2} Q_{2}+\alpha_{3} Q_{3}\right] \\
D_{t}=C_{\mu} \frac{k^{2}}{\varepsilon} \\
Q_{1}=S^{i \alpha} g_{\alpha l} \Omega^{l j}+S^{j \beta} g_{\beta l} \Omega^{l i} \\
Q_{2}=S^{i \alpha} g_{\alpha l} S^{l j}-\frac{1}{3} S^{k \alpha} g_{\alpha m} S^{m \beta} g_{\beta k} \delta_{l}^{i} g^{l j} \\
Q_{3}=\Omega^{i \alpha} g_{\alpha l} \Omega^{l j}-\frac{1}{3} \Omega^{k \alpha} g_{\alpha m} \Omega^{m \beta} g_{\beta k} \delta_{l}^{i} g^{l j} \\
S^{i j}=g^{j \alpha} \nabla_{\alpha} V^{i}+g^{i \alpha} \nabla_{\alpha} V^{j} \\
\Omega^{i j}=g^{j \alpha} \nabla_{\alpha} V^{i}-g^{i \alpha} \nabla_{\alpha} V^{j}
\end{gathered}
$$

モデル係数は, ストレインパラメータSと, ローテイ ションパラメータ $\Omega$ 次のような関数で与える.

$$
\begin{gathered}
\alpha_{1}=-0.1325 f_{M}, \quad \alpha_{2}=0.0675 f_{M}, \\
\alpha_{3}=-0.0675 f_{M} \\
f_{M}=\left[1+0.02 M^{2}\right]^{-1}, \quad M=\max [S, \Omega] \\
C_{\mu}=\min \left[0.09, \quad 0.3 /\left(1+0.09 M^{2}\right)\right] \\
S=\frac{k}{\varepsilon} \sqrt{\frac{1}{2} S^{i \alpha} g_{\alpha j} S^{j \beta} g_{\beta i}}, \Omega=\frac{k}{\varepsilon} \sqrt{\frac{1}{2} \Omega^{i \alpha} g_{\alpha j} \Omega^{j \beta} g_{\beta i}}
\end{gathered}
$$

モデル係数のうち式(17)，（18) は単純せん断流場におけ る乱れ強さの配分に関する実験結果との比較を通じて同

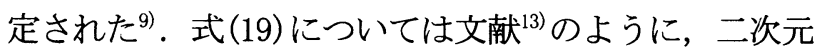
及び三次元流れにおける実現条件から同定した.

\section{（3）計算法の概要}


- Series A

\begin{tabular}{|c||c|c|c|c|c|c|c|}
\hline Run & $\mathrm{A} 1 *$ & $\mathrm{~A} 2$ & $\mathrm{~A} 3$ & $\mathrm{~A} 4 *$ & $\mathrm{~A} 5$ & $\mathrm{~A} 6$ & $\mathrm{~A}^{*} *^{\dagger}$ \\
\hline$\theta$ 注 & $-30^{\circ}$ & $-20^{\circ}$ & $-10^{\circ}$ & $0^{\circ}$ & $10^{\circ}$ & $20^{\circ}$ & $30^{\circ}$ \\
\hline \hline $\mathrm{B}=30 \mathrm{~cm}, \mathrm{~S} / \mathrm{L}=2, \mathrm{~T} / \mathrm{h}=1 / 2, \mathrm{~S}=10 \mathrm{~cm}, \mathrm{~L}=5 \mathrm{~cm}, \mathrm{~h}=8 \mathrm{~cm}, \mathrm{~T}=4 \mathrm{~cm}$ \\
$\mathrm{Q}=4.1 \ell / \mathrm{s}, \mathrm{Slope}=1 / 2000, \quad \mathrm{Fr}=0.19, \quad \mathrm{Re}=1.37 \times 10^{4}$ \\
\hline
\end{tabular}

注) 直角 : $\theta=0$, 上流向 : $\theta<0$, 下流向 : $\theta>0$, B:水路幅

- Series B

\begin{tabular}{|c||c|c|c|c|}
\hline Run & $\mathrm{B} 1$ & $\mathrm{~B}^{*}{ }^{\dagger}$ & $\mathrm{B} 3 *$ & $\mathrm{~B} 4 *$ \\
\hline $\mathrm{S} / \mathrm{L}$ & 1 & 2 & 3 & 4 \\
\hline \hline $\mathrm{B}=30 \mathrm{~cm}, \quad \theta=30^{\circ}, \mathrm{T} / \mathrm{h}=1 / 2, \quad \mathrm{~L}=5 \mathrm{~cm}, \quad \mathrm{~h}=8 \mathrm{~cm}, \quad \mathrm{~T}=4 \mathrm{~cm}$ \\
$\mathrm{Q}=4.1 \mathrm{l} / \mathrm{s}, \mathrm{Slope}=1 / 2000, \quad \mathrm{Fr}=0.19, \quad \mathrm{Re}=1.37 \times 10^{4}$ \\
\hline
\end{tabular}

- Series C

\begin{tabular}{|c||c|c|r|c|}
\hline Run & $\mathrm{C} 1$ & $\mathrm{C}^{*^{\dagger}}$ & $\mathrm{C} 3$ & $\mathrm{C} 4$ \\
\hline $\mathrm{T} / \mathrm{h}$ & $1 / 4$ & $1 / 2$ & $3 / 4$ & $1 / 1$ (非越流) \\
\hline \hline $\mathrm{B}=30 \mathrm{~cm}, \quad \theta=30^{\circ}, \mathrm{S} / \mathrm{L}=2, \quad \mathrm{~S}=10 \mathrm{~cm}, \quad \mathrm{~L}=5 \mathrm{~cm}, \mathrm{~h}=8 \mathrm{~cm}$, \\
$\mathrm{Q}=4.1 \ell / \mathrm{s}, \mathrm{Slope}=1 / 2000, \quad \mathrm{Fr}=0.19, \quad \mathrm{Re}=1.37 \times 10^{4}$ \\
\hline
\end{tabular}

* 冨永らの実験）（PIV）の条件と一致するRun

$\dagger$ Run A7, B2, C21同一条件

\section{a）計算スキーム}

計算法は有限体積法とする。一般曲線座標系において は，計算の単純化と計算機記憶容量の節約のため, レ ギュラー格子あるいはコロケート格子が採用されること が多いが，本研究では計算の安定性と有限体積法への親

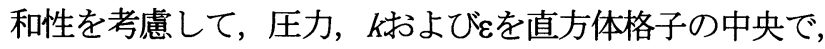
流速ベクトルの成分を側面で定義する完全スタガード格 子系を用いる. 計量テンソル，クリストッフェル記号等 は格子点上で定義し, 計算の過程で必要となる位置の值 については, その都度内挿により求めた。これは, 計算 機メモリの節約のためである.

運動方程式の移流項の離散化にはQUICKを， $k$ および 方程式の移流項にはHybrid法を用いた。 また，運動方程 式の移流項のクリストッフェル記号を含む付加項につい ても, 従来の研究8)にならいコントロールボリュームの 上流側で評価した。時間積分は完全陽解法とし, 二次の Adams Bashforth法を用いる. 圧力は時間ステップ毎に SOLAアルゴリズム ${ }^{14)}$ と同様の収束計算により求める.

\section{b）壁面及び水面の取り扱い}

今回の数值計算の対象が河川流であることを考慮し, 壁面の $k$ とにについては壁関数法で与え, 壁面近傍の流速 は対数則で評価することとした。

水面のには杉山ら ${ }^{15)}$ の提案する次式で評価した.

$$
\varepsilon_{s}=C_{\mu 0}{ }^{3 / 4} k_{s}^{3 / 2} /\left(0.4 \Delta z_{s}\right), \quad\left(C_{\mu 0}=0.09\right)
$$

上式中, 添字 $\mathrm{s}$ は表層の值を, $\Delta z_{\mathrm{s}}$ は水面から定義点ま での距離を表す. 水面のkにはslip条件を課す. また，水 面近傍の鉛直方向の乱れの減衰を考慮するため，次の減 衰関数を渦動粘性係数に乗じる ${ }^{16)}$.

$$
f_{s}=1-\exp \left\{-B(h-z) \varepsilon_{s} / k_{s}^{3 / 2}\right\}, \quad(B=10)
$$

自由水面変動量は, 反変成分表示の基礎式においては次

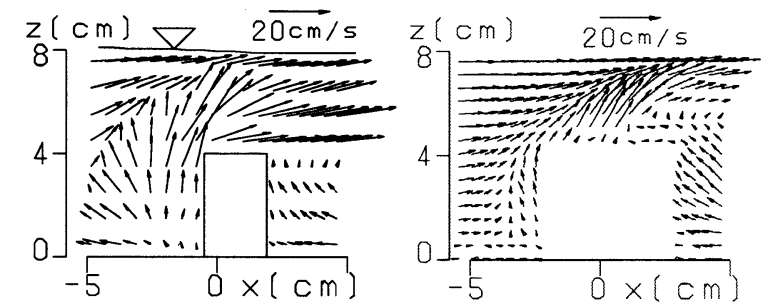

(a) Run A1 左: Cal. 右 : Exp.
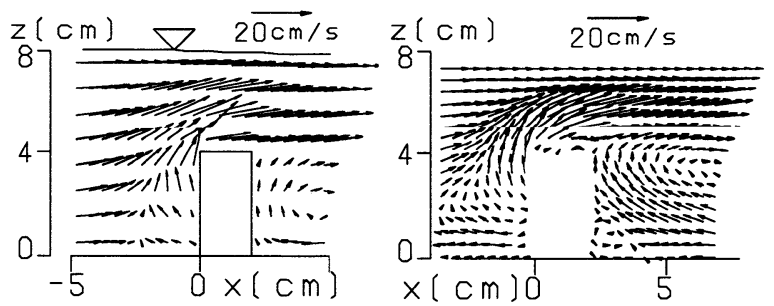

(b) Run A4 左: Cal. 右 : Exp.
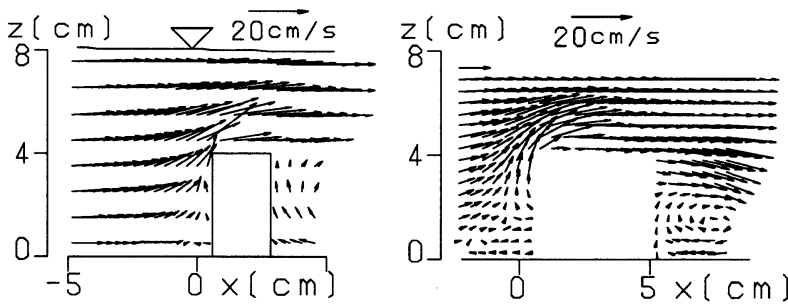

(c) Run A7 左 : Cal. 右 : Exp.

図-2 第 1 水制近傍の綐断流状 $(\mathrm{y}=5 \mathrm{~mm})$

のように極めて簡単な式により計算される,8).

$$
\Delta h=\sqrt{g_{33}} V^{3} \Delta t
$$

上の式で, $\Delta \mathrm{t}:$ 計算時間間隔， $\Delta h: \Delta t$ 時間の水面変動量 を表し，添字 3 は鉛直方向を表わすものとする.

\section{（4）計算の条件}

\section{a) 水理条件}

本研究では連続水制として最も単純な, 形状の等しい 2 つの水制のみが連続して存在する場合を対象とし, 次 の3つの水理パラメータの影響を検討する.

i) $\begin{array}{ll}\theta & \text { : 水制設置角度 }\end{array}$

ii) $\quad \mathrm{S} / \mathrm{L} \quad$ : (S:水制設置間隔， $\mathrm{L}:$ 水制長 $)$

iii) $\quad \mathrm{T} / \mathrm{h} \quad$ : ( $\mathrm{T}$ :水制高, $\mathrm{h}:$ 水深)

これらのパラメータを変化させた表-1に示す 15 通りの条 件のもとで計算を実施した. なお，水制が 2 本の場合と 多数の水制が連続する場合とでは流れ構造が大きく異な る点が指摘されており ${ }^{17)}$ ，水制本数を増やした場合の検 討も不可欠であるが，この点は今後の課題としたい.

\section{b) 計算領域と計算格子}

計算対象領域は水制域の上下流側それぞれ3mの範囲 に設定した. 水平面内の格子は千葉 ${ }^{18)}$ らの方法により作 成し，鉛直方向の格子は，初期条件として底面・水面間 を等間隔で分割し，水制天端高さ $(z=40 \mathrm{~mm})$ より高い 部分の格子については式(23)で計算される水面変動に比 例させて時間ステップごとに変化させる移動格子とした. 横断面内の格子数は各Seriesとも $30(y$ 方向 $) \times 8(z$ 方向 $)$ で 


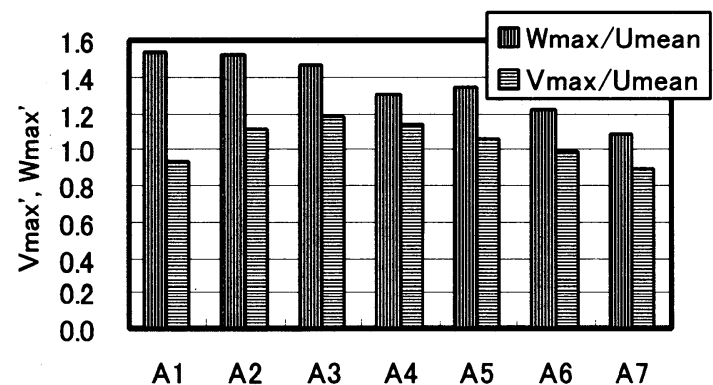

図-3 無次元最大偏心流速

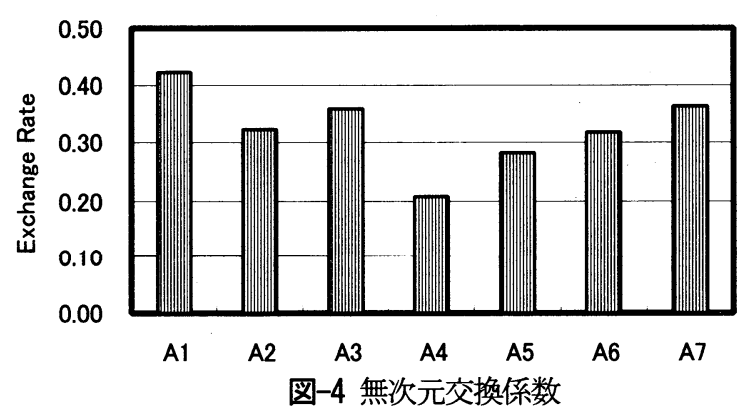

図-4 無次元交換係数

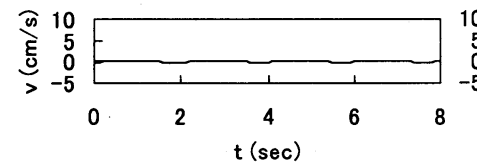

(a) Run $\mathrm{Al}$ (Cal.)

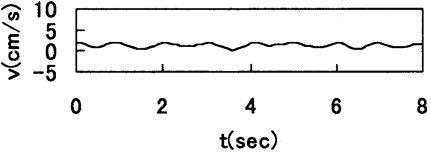

(e) Run A5(Cal.)

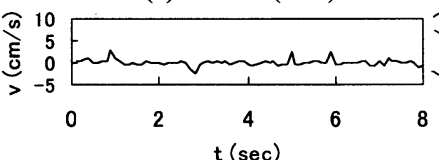

(h) Run Al(Exp.)

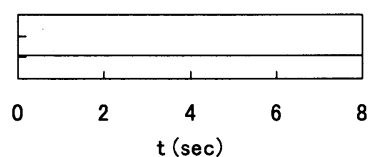

(b) Run A2(Cal.)

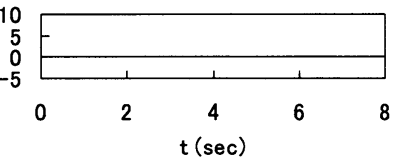

(c) Run A3(Cal.)

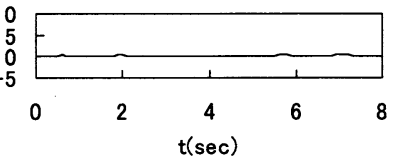

(d) Run A4(Cal.)

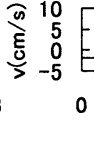

$\begin{array}{rr}0 & 10 \\ \sum_{0}^{5} & 5 \\ > & 0 \\ > & -5 \\ & \end{array}$

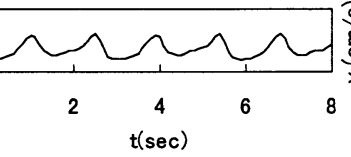

(f) Run A6(Cal.)

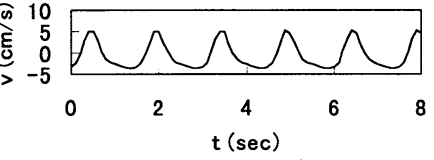

(g) Run A7(Cal.)

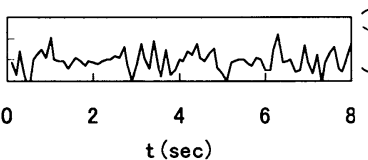

(i) Run A4(Exp.)

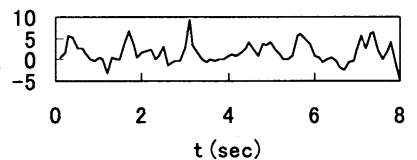

(j) Run A7(Exp.)

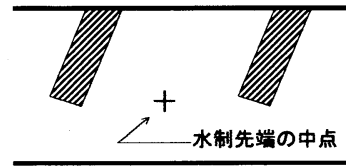

平面位置の説明 図-5 数值解析及び畐永らの実験における横断方向流速 $v$ の時系列（水制先端の中点， $Z=35 \mathrm{~mm}$ ）

あり, 主流方向(x方向)の格子数はSeries A,Cでは104, Series Bでは81(Run B1)〜 108(Run B4)の間で変化させた.

\section{3. 計算結果の考察}

\section{（1）水制角度の影響（Series A）}

水制角度の影響が顕著に現れるのが第 1 水制上方の水 刨ね部である. 図-2にRun A1, A4, A7における側壁近傍 $(\mathrm{y}=5 \mathrm{~mm})$ の鉛直縦断面内の時間平均流況を冨永らの 実験結果とともに示した. 実験はPIVで行われており, 斜め水制の裏側は撮影できないため, ベクトルの表示範 囲が計算結果よりも小さくなっている. Run A1では上方 に強い流れが生じ，水制上流側では逆流が生じているの に対し, Run A7で上昇流, 逆流域ともに小さい. Run $\mathrm{A} 4$ の結果はRun $\mathrm{A} 1$ とA7の中間的な流れとなっている.

従来の研究で, 流砂輸送を支配する底面近傍の流れが 水制角度に依存し，上流向きの場合は水制間への流入が， 下流向きの場合は流出が支配することが指摘された ${ }^{19,20)}$. Series Aにも同様な傾向が見られ，図は省略するが $\theta$ が 大きいほど底面付近の流出が強くなる傾向が示された.

水刨效果は水制の重要な治水的機能である. 水刨ね 効果の水制角度依存性を検討するため, 横断及び鉛直方 向の無次元最大流速 $\mathrm{V}_{\text {max }} / \mathrm{U}_{\text {mean }}, \mathrm{W}_{\text {max }} / \mathrm{U}_{\text {mean }}\left(\mathrm{U}_{\text {mean }}\right.$ : 平均 流速 $=17.1 \mathrm{~cm} / \mathrm{s}$ ）を図-3に示した。この図より，鉛直方 向の水訽ね効果は上流向き水制で大きく, 水平方向につ いては直角に近い水制で最大となることがわかる.

水制域の水質を考える上で水制域の水交換が重要とな
る. $2 つ の$ 水制に挟まれた水塊の無次元交換係数 $\mathrm{R}$ 'を,

$$
R^{\prime}=\frac{1}{V_{d}} \int_{A}\left|U_{r}\right| d a \cdot \frac{S}{U_{\text {mean }}}
$$

と定義する．ここに, $\mathrm{V}_{\mathrm{d}}$ ：水制に挟まれた領域（水制 域）の体積, $\mathrm{U}_{\mathrm{r}}$ : 水制域界面の法線方向流速, $\mathrm{S}$ : 水制 間隔， $\mathrm{A}$ ：水制域界面（xy平面と $\mathrm{xz}$ 平面の合計）を表す. 図-4は各Runの無次元交換俰数を示したものである. 直 角に近い水制では交換率が小さく，水制角度の絶対值が 大きい場合に交換率が大きいことがわかる.

次に非定常性について検討する. 図-5は, Run A1-A7 の横断方向流速 $\mathrm{v}$ の時系列を， 2 つの水制先端を結ぶ線 の中点の $z=35 \mathrm{~mm}$ の位置における值について示す. 図中 には冨永らの実験值（Run A1, A4, A7) をあわせて示す. 計算結果をみると, 上流向き水制ではほぼ定常流となり, 下流向き角度が大きくなるにつれて振幅が大きくなる. これらの特性は実験とある程度適合している.

\section{（2）水制間隔の影響（Series B)}

図-6は, Run B2-B4の $\mathbf{Z}=5 \mathrm{~mm} に お け る$ 時間平均流を計 算と実験で示したものである．計算結果ではいずれの Runも水制域から主流への流出が卓越している. また Run B4では第 1 水制先端の渦が下流側に引き伸ばされて いる. これらの特性は実験結果と良好に一致する. 図-7 はRun B1の計算結果を同様に示したものである. 水制間 の流速が極めて小さく, 流出流の卓越は認められないな ど，Run B2-B4とは異なる流況を呈している。これより， 下流側水制の底面付近で流出流が卓越するのは, 水制間 


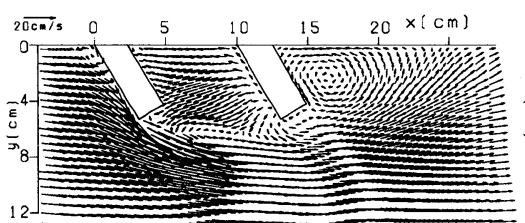

(a) Run B2 (Cal.)

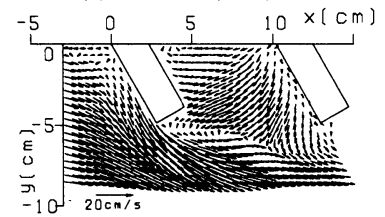

(d) Run B2 (Exp.)

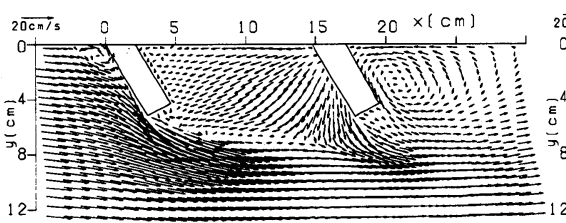

(b) Run B3 (Cal.)

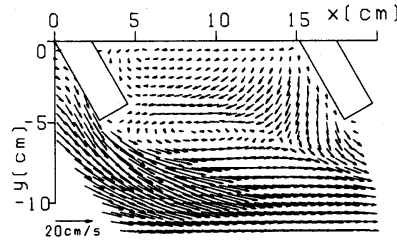

(e) Run B3 (Exp.)

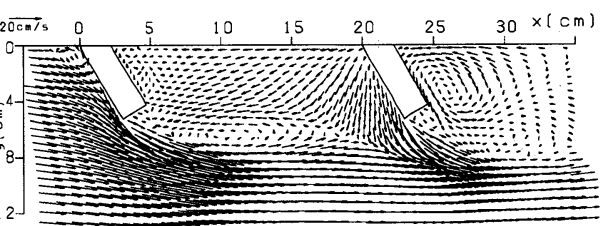

(c) Run B4 (Cal.)

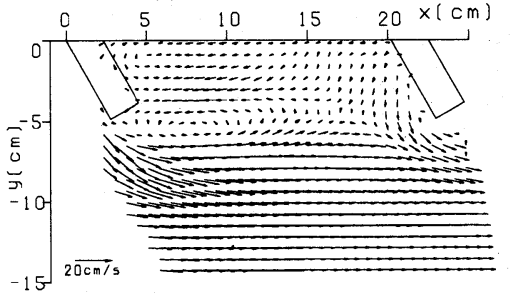

(f) Run B4 (Exp.)

図-6 Series Bにおける水平面内時間平均流速ベクトル $(z=5 \mathrm{~mm})$

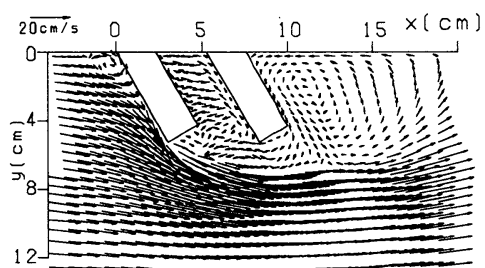

図-7 Run B1の水平面内時間平均流況（ $z=5 \mathrm{~mm} ）$

隔がある程度大きい場合であるといえそうである.

図-8は水制先端中点の $\mathbf{z}=35 \mathrm{~mm}$ における横断流速 $\mathbf{v}$ の時 系列をRun B1-B4で示したものである. Run B1以外では 振動が見られ，B2では規則的な振動となっている．本 流れ場は典型的なimpinging shear layerであり, Rockwell ら ${ }^{21}$ によると，第 1 モード（feedback loop中に 1 個の渦 が存在）のStrouhal数（ $\mathrm{St}_{1}$ ) と第 2 モード（loop中に 2 個渦が存在）のStrouhal数（ $\mathrm{St}_{2}$ ) はほぼ次の範囲になる.

$$
S t_{1}=f L / U_{0} \approx 0.4 \sim 0.6, S t_{2}=f L / U_{0} \approx 1.0 \sim 1.4
$$

ここに， $f$ 周波数, $\mathrm{L}:$ 衝突距離, $\mathrm{U}_{0}$ : 主流流速である. Run B2ではStrouhal数は 0.49 となり, 第 1 モードの範囲内 にある. Run B3では明確な周期は見られない. Run B4 のStrouhal数は1.3であり, 第 2 モードに適合する.これ らの結果より, Run B2とB4の間で周波数ジャンプが生 じており, Run B3はその遷移状態であると推測される.

\section{（3）水制高さの影響（Series C）}

図-9は, Series Cにおける水平面内時間平均流況 （ $z=5 \mathrm{~mm} ）$ ，縦断面内時間平均流況（ $\mathrm{y}=25 \mathrm{~mm} ）$ ，及び 水制先端中点の横断方向流速時系列 $(z=35 \mathrm{~mm})$ を示し たものである. 平面流況に着目すると, Run C2, C3では 水制間から主流部への流出が卓越するのに対し, Run C1 では水制問への流入が卓越している. 従来から下流向き 越流水制の底面付近に水制間からの流出が卓越すること が指摘されてきたが ${ }^{19920)}$, 相対水深如何によっては逆向 きの流れが卓越する可能性が示された．非越流型のRun C4では水制間に平面 2 次元的な循環流が形成せれてい る. 縦断面内の流れに着目すると, Run C1-C3では水制 間に時計回りの循環流が発生する．ところがRun C4につ
Run B1

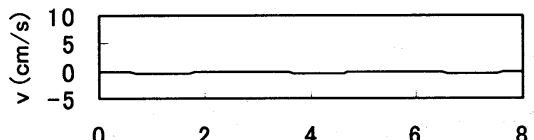

Run B2
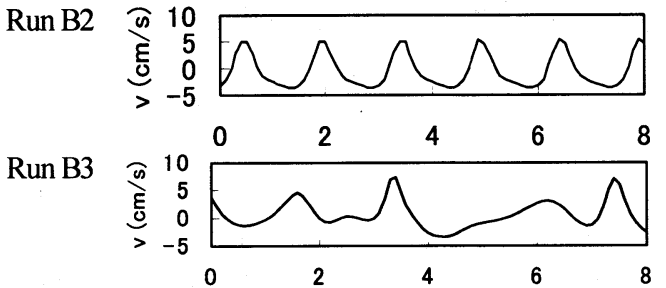

Run B4

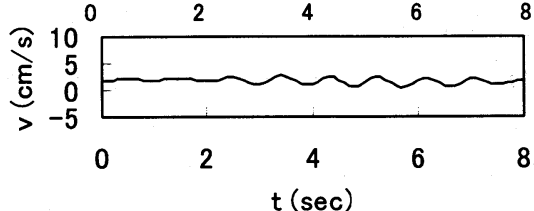

図-8 Series Bの時系列（水制先端中点, $z=35 \mathrm{~mm}$ ）

いては逆に反時計回りの循環流となっており, 越流型と 非越流型で流れのパターンが逆になるのは興味深い. 流 速変動についてみると, 非越流型のRun C4ではほぼ定常 解となっていることから, 水制先端部の混合層よりも水 制上面の混合層の方が非定常性一の関与が大きいといえ そうである. また，Run C2に比べてC1とC3では変動の 振幅が小さい：これは，水制上面の混合層の発達が底面， あるいは水面によって抑制されるためと推測される.

\section{4. まとめ}

本研究は，水制周辺の三次元流れ場における時間平均 特性, 非定常特性について, 水制設計上重要と思われる 3 つの水理パラメータの効果を検討したものである. 本 研究で示された主な結果を次に列挙する.

1. 鉛直方向の水刎ね効果は上流向き水制で最も大きく, 水平方向の水訽効果は直角水制の場合が大きい，

2. 水制域の水交換は設置角度の絶対值が大きくなるに つれて大きくなり, 直角付近で最小となる.

3. 水制の下流向きの角度が大きくなるにつれて, 非定 常性が顕著となる.

4. 越流型水制周辺の非定常性は主に水制上面のせん断 混合層に起因し，その周期はimpinging shear layerの 


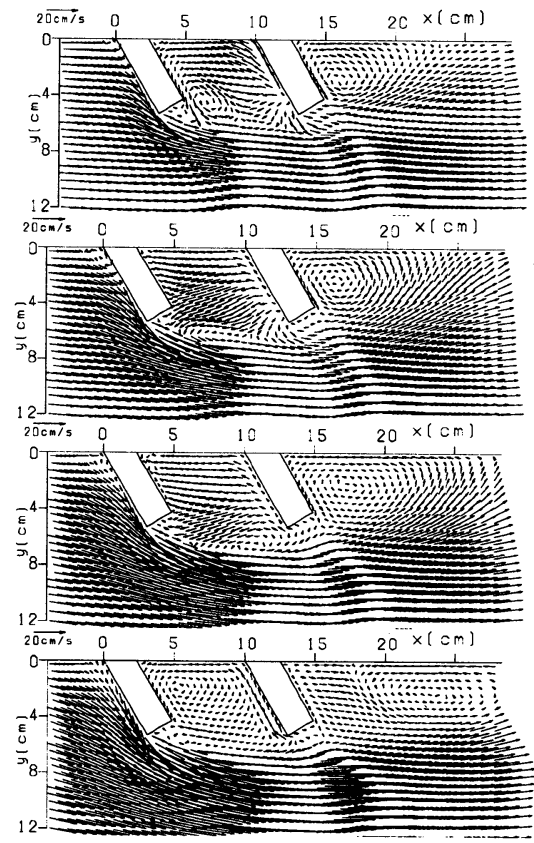

(a) 平面流況 $(z=5 \mathrm{~mm})$,
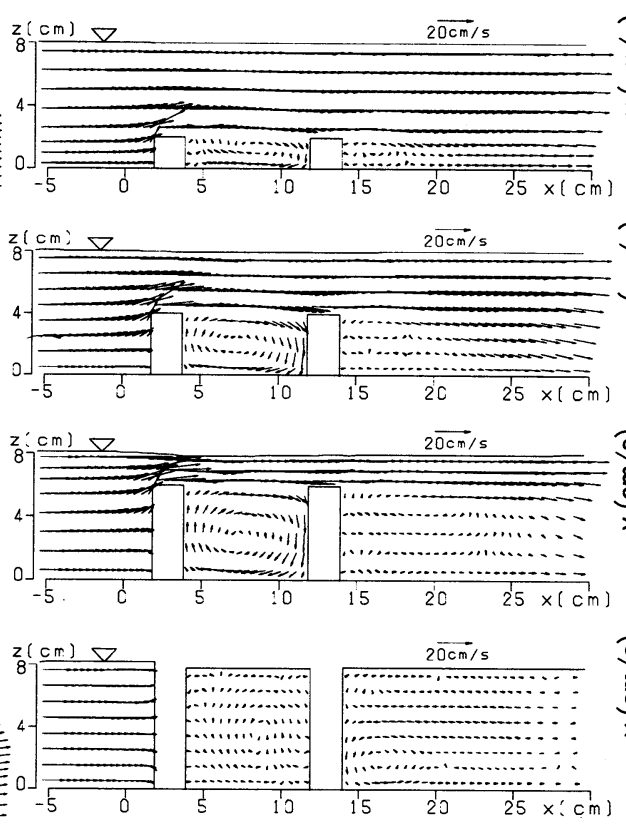

(b) 縦断流況 $(\mathrm{y}=25 \mathrm{~mm})$
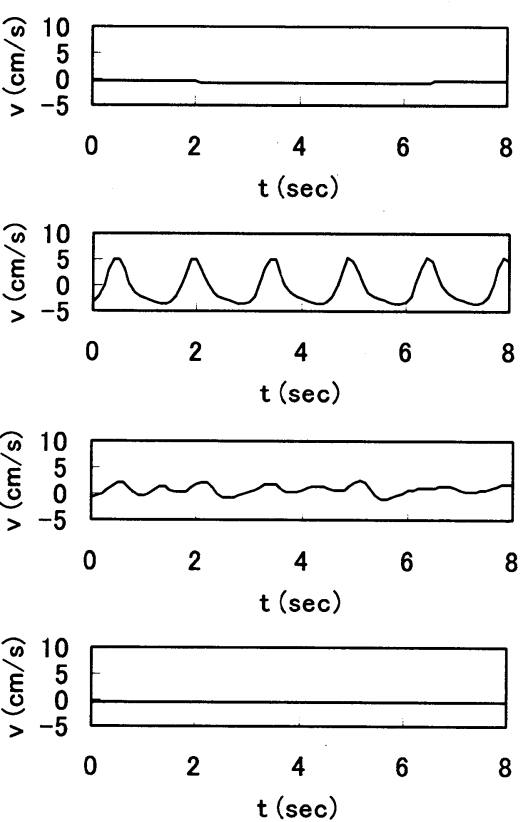

(c) 水制先端中点のv時系列

図-9 Series Cにおける時間平均流況と流速変動（上から順にRun C1,C2, C3,C4）

feedback効果により決まる. $\mathrm{S} / \mathrm{L}=2 \sim 4$ 付近で第 1 モードから第 2 モードへ周波数ジャンプする.

5. 基本的に下流向き水制では底面付近に水制間から主 流部への流出が卓越するが, 越流水深が極端に大き い場合，非越流型の場合などはこの限りではない. これらの結果の普遍性についてはさらに詳細に実験と の比較検証を進めていく必要がある. 今後, 水制周辺の 流砂輸送と水理諸量の関係についても検討していきたい.

\section{参考文献}

1）木村一郎，北村忠紀，熟見哲也，鬼束幸樹，武田誠，庄建 冶朗 : 河川懇談会共同研究「ワンドの水理と河川環境」研 究成果報告書, 2002 .

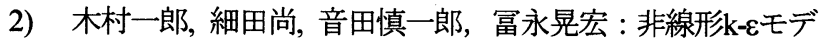
ルによる斜め越流型水制周辺の三次元流況に関する数值解 析, 応用力学論文集, Vol.5, pp.717-726, 2002.

3）木村一郎, 細田尚, 音田慎一郎, 冨永晃宏 : 越流型水制周 辺の非定常三次元流孔構造に及ぼす水制設置角度の影響, 水 工学論文集, Vol.47, pp.717-726, 2003.

4) 冨永晃宏, 井嶋康二, 中野義郎 : 斜め越流型水制周辺の流 れ構造のPIV解析, 水工学論文集, Vol.45, pp.379-384, 2001.

5) 富永晃宏, 井嶋康二：越流型水制周辺の流れ構造に及ぼす 水制間隔の効果, 水工学論文集, Vol.46,pp.475-480, 2002.

6) 木村一郎, 細田尚, 音田慎一郎 : 完全スタガード移動一般 曲線座標系における開水路乱流シミュレータの開発, 四日市 大学環境情報論集, Vol.5, pp.145-170, 2002.

7) 越塚誠一 : 数値流体力学, 培風館, 1997.

8) Takizawa, A., Koshizuka, S. and Kondo, S. : Generalization of physical component boundary fitted co-ordinate (PCBFC) method for the analysis of free-surface flow, International Journal for Numerical Methods in Fluids, Vol.15, pp.1213-1237, 1992.

9) Kimura, I. and Hosoda, T. : A non-linear k- $\varepsilon$ model with realizability for prediction of flows around bluff bodies, International Journal for Numerical Methods in Fluids, Vol.42, pp.813-837, 2003.

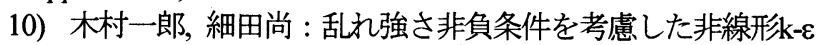

モデルによる立方体周辺の流れの三次元解析, 水工学論文集, Vol.44, pp.599-604, 2000.

11) Hosoda, T., Sakurai, T., Kimura, I. and Muramoto, Y. : 3-D Computations of compound open channel flows with horizontal vortices and secondary currents by means of non-linear k- $\varepsilon$ model, $J$. Hydroscience and Hydraulic Eng., Vol.17, No.2, pp.87-96, 2000.

12) Gatski, T.B. and Speziale, C.G. : On explicit algebraic stress models for complex turbulent flows, J. Fluid Mech., Vol.254, pp.59-78, 1993.

13) Hosoda, T., Kimura, I. and Shinichiro, O. : Some necessary conditions for a non-linear $k-\varepsilon$ model in classified flow patterns with a singular point, Proc. $2^{\text {nd }}$ Internatilnal Symp. on Turbulence and Shear Flow Phenomena, Stockholm, Vol.3, pp.155-160, 2001.

14) Hirt, C. W., Nichols, B. D. and Romero, N. C. : SOLA-A Numerical solution algorithm for transient fluid flows, Los Alamos Scientific Report, LA-5852, 1975.

15) 杉山均, 秋山光庸, 松原珠 : 複断面開水路内の乱流構造解 析と縦渦生成に関する研究, 土木学会論文集, Vol.515, II-31, pp.55-65, 1995.

16) 細田尚 : 開水路流れにおける乱流拡散機構に関する水理学 的研究, 京都大学博士論文, 1990 .

17) Kimura, I., Hosoda, T., Onda, S. and Tominaga, A.: 3D numerical analysis of unsteady flow structures around inclined spur dikes by means of a non-linear k- $\varepsilon$ model, Proc. Int. Symp. on Shallow Flows, Delft, III, pp.205-212, 2003.

18）千葉賢, 武本行正 : 伊勢湾数值シミュレータの研究・第 2 報一GUI環境を利用した 2 次元構造格子生成プログラ人の開 発一, 四日市大学環境情報論集, Vol.2, No.2, pp.103-126, 1999.

19）山下洋平, 伊藤昭文, 武田誠, 松尾直規 : 木曽川ワンド群 の堆積状況の支配的要因に関する研究，土木学会中部支部講 演概要集, pp.237-238, 2001.

20) 木村一郎他 : 木兽川感潮域に設置された水制群周辺のワン ド形成過程と河川環境に関する共同研究，河川技術論文集， 第 8 巻, pp.365-370, 2002.

21) Rockwell, D. and Naudascher, E.: Review - Self-sustaining oscillations of flow past cavities, Transaction of the ASME, J. Fluid Eng., Vol.100, pp.152-165, 1978.

(2003. 9. 30受付) 